\title{
Numerical approach about the effect of the corrosion on the mechanical capacity of the reinforced concrete beams considering material nonlinear models
}
Abordagem numérica sobre o efeito da corrosão de armaduras na capacidade mecânica de vigas em concreto armado ao longo do tempo considerando modelos não lineares dos materiais
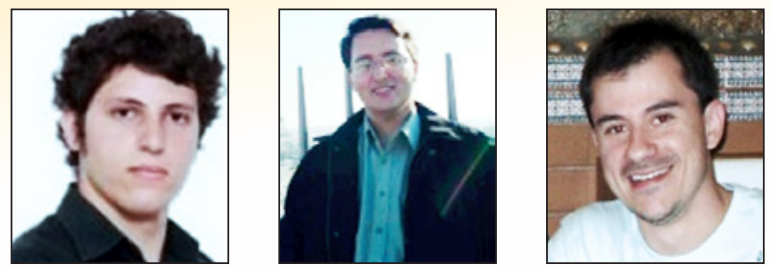

G. P. PELLIZZER a gpais@usp.br

E. D. LEONEL a edleonel@sc.usp.br

C. G. NOGUEIRA b cgnogueira@feb.unesp.br

\begin{abstract}
Every structure is subjected to the effects of time and environment on which they are located. The consideration of these effects and their consequences in design phase is called nowadays as durability analysis of the structural system. The corrosion of the reinforcement steel through the chloride penetration inside the concrete is the main cause of the lifetime deterioration of the reinforced concrete structures. As a direct consequence, the corrosion affects the resistant capacity of the structural elements as the process evolves over time. Therefore, the appropriate prediction of the structural lifetime depends directly of the prevision capacity of those effects over the behavior of the structural systems. In this work, a mechanical model that combines the corrosion effects over the reinforcement and the concrete and steel material nonlinear responses is proposed to predict the resistant loss of reinforced concrete beams over the time. The steel and concrete nonlinear behavior was modeled by model based on unidimensional plasticity theory and damage mechanics, respectively. The Fick's laws and empirical methods based on the Faraday's laws were used to represent chloride penetration inside concrete and reinforced degradation, respectively. A simplified process was adopted to simulate the corrosion beginning in different times over the structure. The results showed that the rate of loss resistant capacity of the analyzed beam is higher in the first years after the beginning of corrosion and tend to stabilized in subsequent years. Furthermore, the structural behavior is very sensitive regarding the considered corrosive effects in the analyses.
\end{abstract}

Keywords: reinforced concrete beams, structural integrity, mazars's damage model, fem, corrosion, Fick's law.

\section{Resumo}

Toda estrutura está sujeita aos efeitos do tempo e ambiente na qual estão inseridas. A consideração desses efeitos e suas consequências na fase de projeto é o que se chama atualmente de análise da durabilidade do sistema estrutural. A corrosão do aço das armaduras através da penetração de cloretos no concreto é a principal causa de deterioração ao longo do tempo em estruturas de concreto armado. Como consequência direta, a corrosão afeta a capacidade resistente dos elementos estruturais à medida que o processo evolui no tempo. Portanto, a previsão adequada da vida útil estrutural depende diretamente da capacidade de previsão desses efeitos sobre o comportamento dos sistemas estruturais. Neste trabalho, um modelo mecânico que combina os efeitos da corrosão de armaduras e as respostas não linear dos materiais aço e concreto é proposto com o objetivo de prever a perda de resistência de vigas em concreto armado ao longo do tempo. O comportamento dos materiais acco e concreto foram simulados por modelos baseados na teoria da plasticidade unidimensional e mecânica do dano, respectivamente. As leis de Fick e métodos empíricos fundamentados nas leis de Faraday foram utilizados para representar a entrada de cloretos e degradação das armaduras, respectivamente. Um processo simplificado foi adotado para a simulação do início da corrosão em tempos diferentes ao longo da estrutura. Os resultados mostraram que a taxa de perda de capacidade resistente da viga analisada é maior nos primeiros anos após o início da corrosão e tendem a se estabilizar nos anos posteriores. Além disso, o comportamento estrutural é muito sensível em relação aos efeitos corrosivos considerados nas análises.

Palavras-chave: vigas em concreto armado, integridade estrutural, modelo de dano de mazars, mef, corrosão, lei de Fick. 


\section{Introduction}

Nowadays, the structural design cannot be restricted to the mechanical behaviour assessment and its dependence upon the external loading. In reinforced concrete structures, particularly, the design must account for the aging and the environmental effects, which strongly affect the structural system behaviour and its durability. Among the major environmental mechanisms that cause aging and mechanical degradation in reinforced concrete structures, it is worth citing: leaching, sulphates expansion, alkali-aggregate reaction, reinforcements' depassivation due to the carbonation and the chlorides ingress and the reinforcements' corrosion (ABNT NBR 6118:2014 [4]).

The reinforcements' corrosion is the most important phenomenon that cause the mechanical degradation of reinforced concrete structures along time. This phenomenon reduces the mechanical structural strength along time and consequently the structural durability (CEB [11]; Gonzalez et al. [15]; Val and Melchers [33]; Val and Stewart [34]; Apostolopoulos and Papadakis [3]; Suo and Stewart [31]; Bastidas-Arteaga et al. [6]; Zhang et al. [37]). The electrochemical corrosion leads to the loss of reinforcements' cross-section area and contributes for increasing the concrete cracking and spalling. Moreover, this type of corrosion provides the reduction of the reinforcements' yield strength, ductility and adherence to the concrete. These effects may change the predominant failure mode of reinforced concrete structures along time. In addition, it may transform ductile failure mode in brittle failure behaviour as presented by Liberati et al. [17], Apostolopoulos and Papadakis [3], Almusallam [1] and Almusallam et al. [2].

Mehta and Monteiro [21] analysed several reinforced concrete bridges in the US from the 90's. Their study shows that $39 \%$ of the analysed bridges have structural problems caused by the reinforcements' corrosion. The annual global cost associated to the corrosion problems were estimated on 1.8 trillion dollars, which represents $3-4 \%$ of the GDP of industrialized countries (Schmitt [30]). Therefore, the accurate durability assessment in the design phase may reduce satisfactorily the cost associated to the problem.

To mitigate the reinforcements' corrosion problems in the design phase, the designers have prescribed adequate concrete cover values, water/cement $(\mathrm{w} / \mathrm{c})$ ratio and cement types. However, the durability requirements of reinforced concrete structures cannot be based, exclusively, on these parameters. Then, the accurate approaches for predicting and quantifying the mechanical damage caused by the environment must be developed. Moreover, these approaches must be robust enough for predicting and quantifying the damage evolution along time (Biondini et al. [8]; Biondini and Vergani [10]). In this regard, the application of numerical methods with complex mechanical material models is an interesting alternative. Particularly, the use of the Finite Element Method (FEM) coupled to elastoplastic and damage mechanics models is an accurate approach for modelling the reinforced concrete structures, Liberati et al. [17]. Therefore, these requirements justify the development of the present research, in which a mechanical model for reinforcements' corrosion modelling is proposed.

Empirical approaches for the representation of mechanical degradation phenomena associated to reinforcements' corrosion such as: cross-section reduction area, decrease of the yield strength and ductility, concrete spalling and adherence loss have being pro- posed in the literature, (Du et al. [13]; Ozbolt et al. [25]; Biondini et al. [9]; Liberati et al. [17]; Biondini and Vergani [10]; Nogueira et. al [24]). In this study, a numerical model based on the coupling of the FEM with elastoplasticity and damage mechanics theories is proposed for modelling the mechanical behaviour of reinforced concrete beams. It is used a frame FEM element in which elastoplasticity describes the mechanical behaviour of reinforcements and damage mechanics the mechanical behaviour of concrete. To represent the chloride ingress, the Fick's law is utilized. Moreover, empirical approaches are coupled to such a model to represent the reinforcements' cross-section area reduction and the reduction over the reinforcements' yield strength along time. The proposed model enables modelling the mechanical degradation effects on concrete in terms of the damage evolution, as the corrosion progresses along time. Moreover, the empirical models for the steel corrosion coupled to elastoplasticity approach enables the modelling of the mechanical degradation on the reinforcements. Thus, the proposed model enables the accurate determination of the mechanical structural resistance along time, which is the main contribution of this study.

\section{Corrosion phenomenon modelling}

\subsection{Chloride diffusion into concrete pores}

The chloride ions penetrate into concrete pores by the transport of contaminated water, ionic diffusion and capillary absorption (Neville [22]). These phenomena are represented properly through the ionic diffusion process based upon the Fick's laws (Vu and Stewart [36]; Samson et al. [29]; Val et al. [35]; Guzmán et al. [16]). Fick's second law is an appropriate approach for describing the chloride ingress once the chloride concentration along the material depends upon the external concentration and the time. Thus, this approach represents a non-steady state flow. The materials governed by the Fick's law obey to the following characteristics: homogeneous, isotropic and chemically inert. Moreover, the materials properties are kept constant in all directions along time (Crank [12]). The Fick's laws describe the transport of chlorides into concrete (ions flow F) using a unitary material section per unit of time. This flow is proportional to the chloride concentration gradient, which is measured in the perpendicular direction of the surface exposed to the environment (Tuutti [32]). The flow is written as follows:

$F=-D_{d} \frac{\partial C}{\partial x}$

where: $D_{d}$ is the concrete diffusion coefficient. The negative sign indicates that the flow occurs on the opposite direction of the chloride concentration increase.

Once the concrete is a porous material, the chloride concentration grows into concrete pores along time, which characterizes a non-steady flow. The Fick's second law accounts for this effect, because it considers the flow variable along the material depth and along time. The application of the mass balance principle enables writing the Fick's second law as follows:

$\frac{\partial C}{\partial t}=\frac{\partial}{\partial x}\left(-D_{d} \frac{\partial C}{\partial x}\right)$ 
The diffusion coefficient $D_{d}$ changes along time for several types of materials. However, for the reinforced concrete, this parameter may be assumed as constant (Crank [12]). For such a case, the Equation (2) is rewritten as follows:

$\frac{\partial C}{\partial t}=-D_{0} \frac{\partial^{2} C}{\partial x^{2}}$

Then, $D_{d}$ becomes $D_{0}$, which does not vary along time. The solution of this differential equation for a semi-infinite domain subjected to an uniform concentration at the exterior surface is given by:

$C(x, t)=C_{0} \operatorname{erfc}\left[\frac{x_{c}}{2 \sqrt{D_{0} t}}\right]$

in which: $\mathrm{C}(\mathrm{x}, \mathrm{t})$ is the chloride concentration at a given material depth and time; $\mathrm{C}_{0}$ is the chloride concentration at the exterior surface; $x_{c}$ is the depth inside the concrete where the concentration is evaluated; $t$ is the time instant considered; erfc is the complementary Gauss error function.

To determine the time for corrosion initiation, the $C(x, t)$ has to be equal to the threshold concentration value $\left(\mathrm{C}_{\text {lim }}\right)$, which causes the reinforcements depassivation. Moreover, the $x_{c}$ variable has to be equal to the cover depth. Thus, Equation (4) is rewritten for determining the time for corrosion initiation, $t_{R}$, as follows:

$t_{R}=\frac{1}{D_{0}}\left\{\frac{x_{c}}{2 e r f c^{-1}\left[C_{\text {lim }} / C_{0}\right]}\right\}^{2}$

$\mathrm{Vu}$ and Stewart [36] recommend the threshold concentration value with mean $0.9 \mathrm{~kg} / \mathrm{m}^{3}$ and coefficient of variation of $19 \%$. Mehta and Monteiro [21] recommend $\mathrm{C}_{\text {lim }}$ varying from 0.6 to $0.9 \mathrm{~kg}$ of $\mathrm{Cl}^{-}$by cubic meter of concrete. There are several formulations available in the literature for determining the coefficient of diffusion, $D_{0}$. The assessment of this coefficient accounts for the following parameters: the w/c ratio, aggregate/cement $\left(a_{g} / c\right)$ ratio, specific mass of aggregates $\left(r_{g}\right)$ and specific mass of cement $\left(r_{c}\right)$ (Papadakis et al. [26]; Matsumura et al. [18]). In the present study, the model pro-

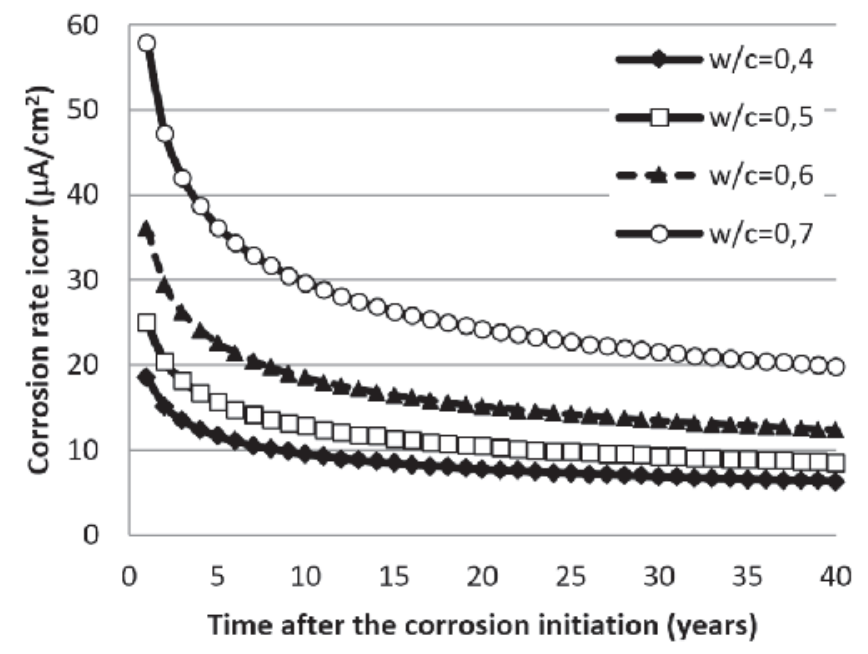

\section{Figure 1}

Evolution of the corrosion rate along time $\left(t_{p}\right)$ considering cover depth of $4 \mathrm{~cm}$ posed by Bentz et al. [7] is utilized for determining the coefficient of diffusion. This model predict $D_{0}$ as follows:

$D_{0}=10^{-10+4.66(w / c)}$

where: $D_{0}$ is given in $\mathrm{cm}^{2} / \mathrm{s}$ (square centimetre per second).

Corrosion effects upon the reinforcements cross-section area

Val and Melchers [33] presented an approach for evaluating the reinforcements' cross-section area during the corrosion process. The uniform and pitting corrosion cases were accounted. However, in the present study only the uniform corrosion case was addressed. In this corrosion case, the loss of reinforcements' cross-section area is determined as follows:

$\Delta A_{S}\left(t_{p}\right)=\frac{\pi\left(\varphi_{0}-0.0232 i_{\text {corr }} t_{p}\right)^{2}}{4}$

where: $\mathrm{i}_{\text {corr }}$ is the corrosion rate given in $\mu \mathrm{A} / \mathrm{cm}^{2} ; \varphi_{0}$ is the noncorroded rebar diameter in $\mathrm{cm}$; $\mathrm{t}_{\mathrm{p}}$ is the time in years from the corrosion start.

The cross-section of general reinforced concrete structures is composed by $n$ steel rebar. Therefore, the reinforcements' updated area along time $\left(A_{S}\right)$ is determined as follows:

$A_{S}\left(t_{p}\right)=\sum_{i=1}^{n}\left[\frac{\pi \varphi_{0, i}^{2}}{4}-\Delta A_{S}\left(t_{p}\right)\right]$

The corrosion rate depends, majorly, on the oxygen and water available in the environment. However, another parameters such as: w/c ratio, concrete cover depth, relative moisture, temperature and atmospheric conditions, have an important hole over the corrosion rate. The corrosion rate is predicted by the models proposed in Stewart and $\mathrm{Vu}$ [36]. These researches proposed one classical model and one improved approach, which accounts for the time of corrosion initiation, $\mathrm{t}_{\mathrm{p}}$. The models proposed by Stewart and $\mathrm{Vu}$ [36] are, respectively, the presented below:

$i_{\text {corr }}=\left[\frac{37.8(1-w / c)^{-1.64}}{x_{c}}\right]$

$i_{\text {corr }}\left(t_{p}\right)=\left[\frac{37.8(1-w / c)^{-1.64}}{x_{c}}\right] 0.85 t_{p}^{-0.29}$

where: $x_{c}$ in the concrete cover in $\mathrm{cm}$; w/c is the water/cement ratio. The $\mathrm{i}_{\text {corr }}$ in both equations is given in $\mu \mathrm{A} / \mathrm{cm}^{2}$ (microampere per centimetre square).

The Figures 1 and 2 illustrate the evolution of the corrosion rate along time by varying, respectively, the w/c ratio and assuming constant the cover depth and by varying the cover depth keeping constant the $w / c$ ratio. The influence of the $w / c$ ratio upon the corrosion rate is higher than the cover depth. The ABNT NBR 6118:2014 [4] recommends (in the item 7.4.2) threshold values for the w/c ratio in reinforced and prestressed concrete structures according to the environmental aggressiveness class (CAA). The CAA III corresponds to the regions with strong aggressiveness and large risk of mechanical degradation, as observed in industrial and marine zones. For this case, the maximum w/c ratio permitted is 0.55 for reinforced concrete and 0.50 for prestressed concrete. The minimum cover depth value predicted by ABNT NBR 6118:2014 [4] in 
the same aggressiveness class, for columns and beams, is $4 \mathrm{~cm}$ and slabs $3.5 \mathrm{~cm}$. Because the corrosion rate depends strongly on these parameters, it is worth adopting in the design phase fair values for $w / c$ ratio and cover depth. The use of adequate $w / c$ ratio and concrete depth lead to a short increase on the structural cost if compared with the repair cost required in the case of failure.

\subsection{Corrosion effects upon the steel strength}

The corrosion process causes the reduction of the reinforcements yield strength along time. This change is associated to the modifications on the steel internal microstructure. Du et al. [13] accomplished experimental analyses for modelling the steel yield stress evolution during the corrosion. These researchers varied the rebar diameter, type of rebar (smooth or ribbed), environmental conditions (exposed rebar or immersed into the concrete) in the study. Based on the experimental responses achieved in their study, Du et al. [13] proposed the following equation for quantifying the steel yield stress along time:

$\sigma_{y}=\left(1-0.005 Q_{c o r r}\right) \sigma_{y 0}$

where: $Q_{\text {corr }}$ is the amount of reinforcement corrosion in $\% ; s_{y 0}$ and $\mathrm{S}_{\mathrm{y}}$ are, respectively, the yield strength of the non-corroded steel and corroded steel. $Q_{\text {corr }}$ is evaluated as follows:

$Q_{\text {corr }}=0.046 \frac{i_{\text {corr }}}{\varphi_{0}} t_{p}$

The rebar diameter required in Equation (12) is provided in millimetres.

\section{Mechanical modelling}

\subsection{Mechanical resistance assessment of reinforced concrete beams utilizing the ABNT NBR 6118:2014}

The ABNT NBR 6118:2014 proposes models and criteria for designing reinforced concrete structures. In the context of reinforced concrete beams, this design code do not predict, explicitly, any

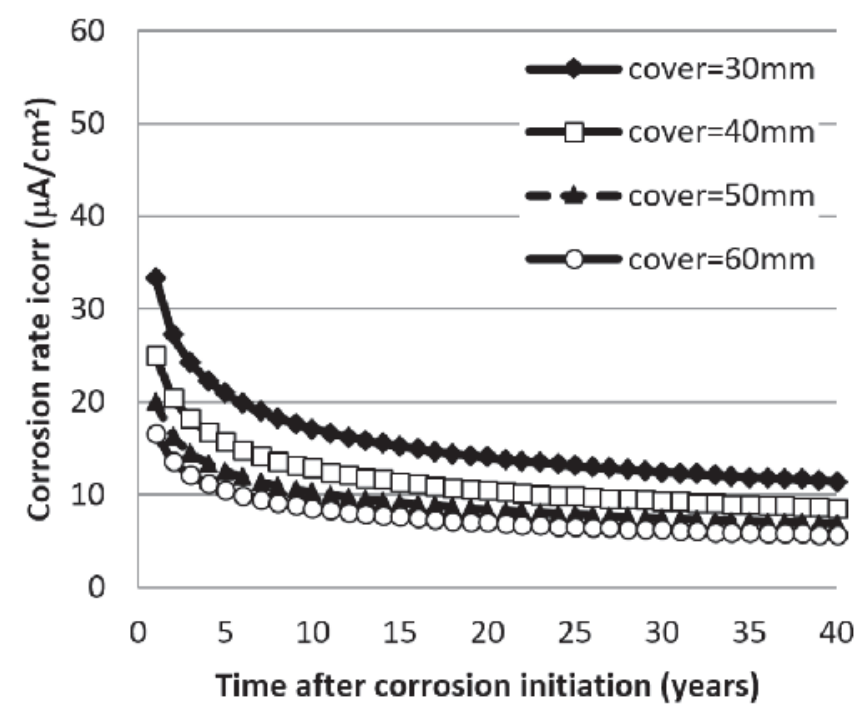

Figure 2

Evolution of the corrosion rate along time $\left(t_{p}\right)$ considering $\mathrm{w} / \mathrm{c}$ of 0.5

criteria for nonlinear analysis. Nevertheless, the mechanical responses predicted by the ABNT NBR 6118:2014 was utilized in the present study. These responses are compared against the results provided by the mechanical model proposed in this study, which applies FEM, damage mechanics and elastoplasticity.

The formulation proposed by the ABNT NBR 6118:2014 is based on the following assumptions:

a) structural cross-sections remain plane until structural failure and normal strains along cross-section high have linear distribution;

b) concrete and reinforcements have perfect adherence. Bondslip behaviour is not considered;

c) the mechanical contribution of tensile concrete is not accounted;

d) the shortening in failure conditions for non-fully compressed concrete is equal to $3.5 \%$ (domains 3,4 and $4 a$ );

e) the maximum elongation allowed for tensile reinforcement is

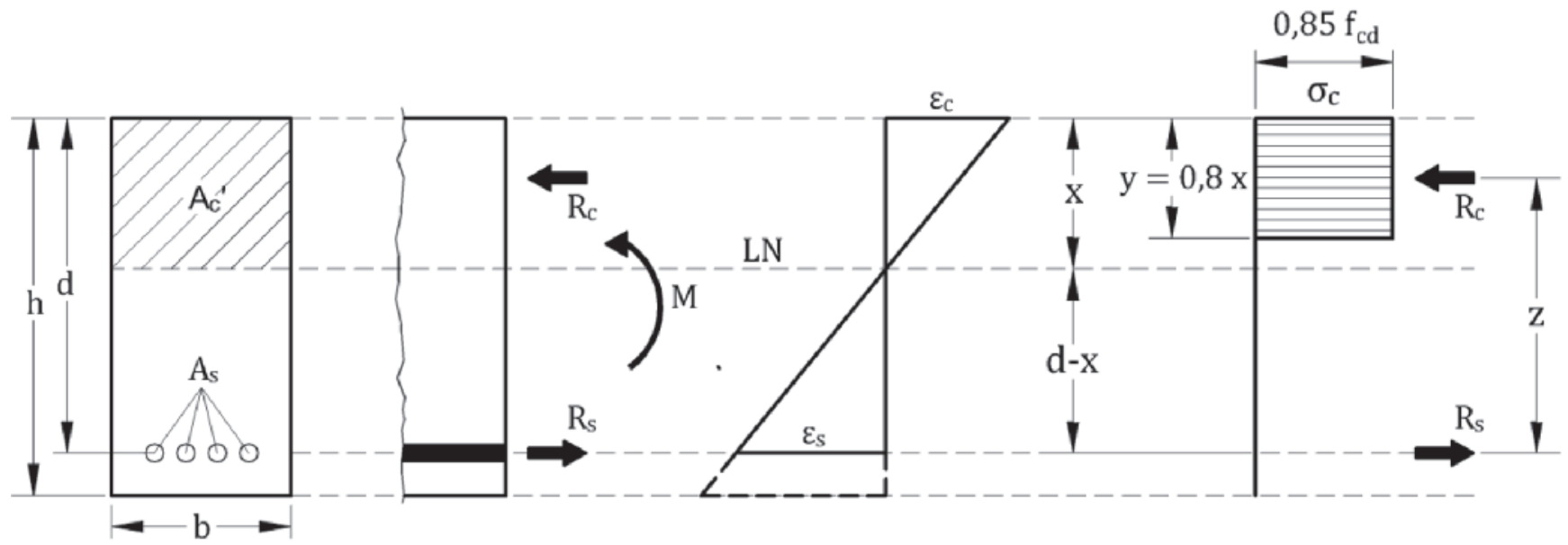

Figure 3

Stresses and strains in a rectangular cross-section with simple reinforcements' case 


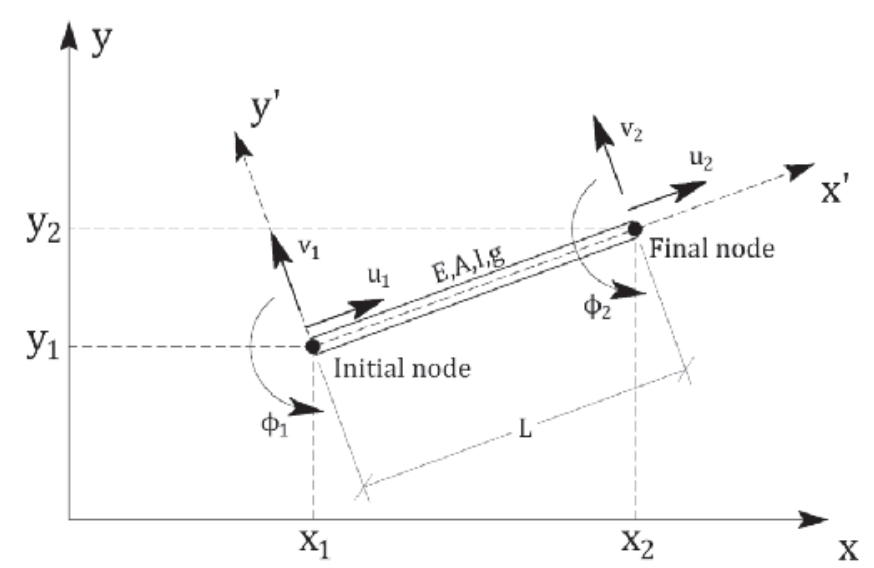

Figure 4

Finite element utilized

$10 \%$. This value is defined to prevent excessive plastic strains;

f) the compression concrete strength is lower than $50 \mathrm{MPa}$ (group I defined into ABNT NBR 6118:2014) with rectangular compression stress distribution.

Figure 3 presents an usual reinforced concrete cross-section, in which the variables required for the resistant bending moment evaluation are illustrated.

where: $h$ and $d$ are the cross-section height and useful height, respectively. $\mathrm{b}$ is the cross-section width. Ac' and As are the compressed concrete cross-section area and the reinforcements area, respectively. $R_{C}$ and $R_{S}$ are the resultant axial forces over the concrete and reinforcements, respectively. $M$ is the applied bending moment. NA defines the neutral axis and $x$ the NA position at the cross-section. $\varepsilon_{C}$ $\mathrm{e}_{\mathrm{S}}$ indicate, respectively, the longitudinal normal strain at the most compressed concrete fibre and at the tensile steel. Finally, $\sigma_{\mathrm{C}}$ represents the compression stress at the most compressed concrete fibre, which in the ultimate limit state is equal to $0.85 \mathrm{f}_{\mathrm{cd}} ; \mathrm{f}_{\mathrm{cd}}$ corresponds to the concrete design strength given by $f_{c k} / 1.4$.

Once the problem evolves a simple bending case, the resultant forces from the concrete and the reinforcements must be equal, $R_{C}=R_{S}$, in order to assure the equilibrium condition. Such a forces are defined as follows:

$R_{c}=0.68 b x f_{c d}$

$R_{s}=f_{y d} A_{s}$

where: $f_{y d}$ is the design reinforcements' yield stress, which is given by $f_{y k} / 1.15$.

The bending moment provided by $R_{C}$ and $R_{S}$, named resistant bending moment $\left(M_{R}\right)$, must be equal to the applied bending moment, $M$, to assure the equilibrium. Therefore:

$M=M_{R}=R_{c} Z=R_{s} Z$

Once $z=d-0.4 x$, the Equations (13) and (14) are rewritten, which enables writing Equation (15) as follows:

$M=0.68 b x f_{c d}(d-0.4 x)$
The solution of Equation (16) enables determining the neutral axis as follows:

$x=1.25 d\left[1-\sqrt{1-\frac{M}{0.425 b d^{2} f_{c d}}}\right]$

The reinforcements' cross-section area is evaluated using the Equations (17) and (14), which results:

$A_{S}=\frac{M}{f_{y d}(d-0.4 x)}$

Finally, the resistant bending moment for a rectangular cross-section with reinforcements' cross-section area known, is determined as follows:

$M_{R}=0.408 b x^{2} f_{c d}=A_{S} f_{y d}(d-0.4 x)$

\subsection{Mechanical modelling based on the coupling of FEM, damage mechanics and elastoplasticity}

In the present study, a numerical mechanical model is proposed, which couples the FEM, damage mechanics and elastoplasticity for describing the mechanical behaviour of reinforced concrete structures. In this model, the damage mechanics represents the nonlinear mechanical behaviour of the concrete whereas the elastoplasticity describes the mechanical behaviour of the reinforcements. Both approaches are included in a FEM framework based on frame elements. The mechanical effects caused by the corrosion, reinforcements' cross-section reduction area and yield strength reduction along time, are included in this model.

The one-dimensional finite frame element with two nodes (one at each end) and three degrees of freedom per node is utilized, as presented in Nogueira et al [24]. The degrees of freedom per node are the following: two displacements ( $\mathrm{u}$ in $\mathrm{x}$ and $\mathrm{v}$ in $\mathrm{y}$ ) and one rotation ( $\phi$ in $\mathrm{z}$ ), as illustrated in Figure 4.

where: $A$ and $I$ are, respectively, the cross-section area and the inertia moment; $g$ is the Weaver's constant, which accounts for the shear strains in the Timoshenko's theory.

The nonlinear mechanical behaviour of the concrete is described consistently by the damage mechanics theory. Particularly, the Mazars's damage model [19] represents accurately the mechanical degradation processes in this material, which occurs, majorly, due to the cracking.

The Mazars's damage model [19] was proposed by assuming that mechanical damage occurs only by elongations. Thus, the material damage evolves if at least one of the main strains components is positive. Moreover, the mechanical damage is isotropic and represented by a scalar variable $D$. This variable ranges from 0 to 1 , in which 0 represents mechanical integrity and 1 indicates the complete mechanical damage. The residual plastic strains are not accounted.

The criterion utilized for verifying the damage evolution at a given material point is written as follows:

$f(\tilde{\varepsilon}, D)=\tilde{\varepsilon}-\hat{S}(D) \leq 0$ 
$\sigma$

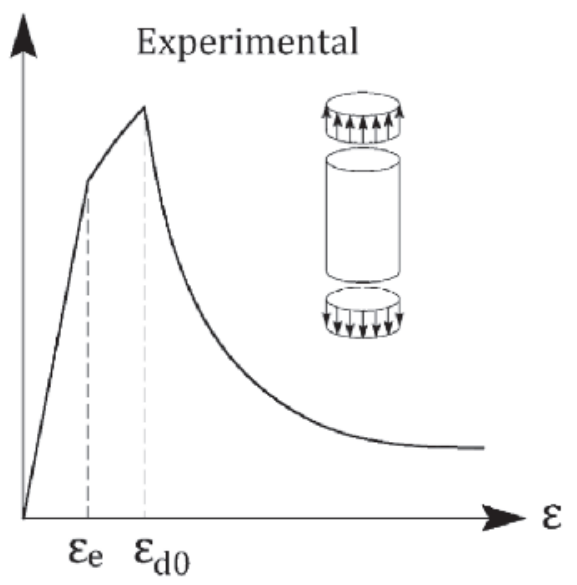

$\sigma$

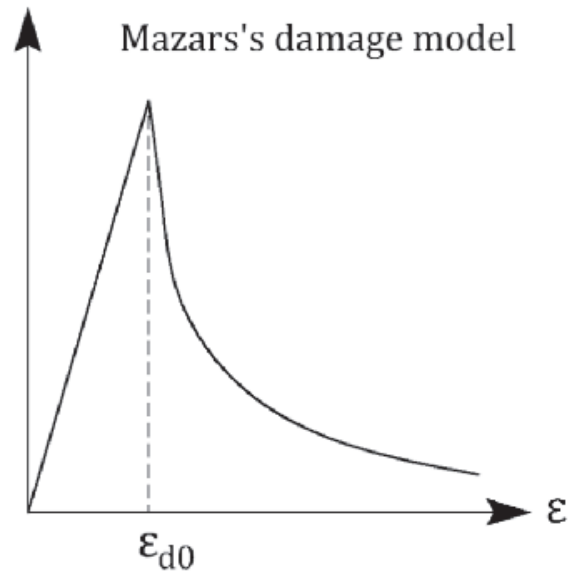

\section{Figure 5}

Constitutive concrete law during a tensile test (left) and Mazars's damage model [19] (right)

where: $\varepsilon$ is a measure of the local equivalent strain; $\hat{S}(D)$ is the equivalent strain as a function of the damage; $D$ is the scalar damage variable.

In the analysis beginning, $\hat{S}(D)=\varepsilon_{d 0} \cdot \varepsilon_{d 0}$ is the normal strain associated to the tensile concrete strength, as illustrated in Figure 5. During the incremental iterative equilibrium procedure, $\hat{S}(D)$ assumes the value of the equivalent strain at the last converged load step.

The equivalent strain at a given material point is defined as follows:

$\tilde{\varepsilon}=\sqrt{\left(\varepsilon_{1}\right)_{+}^{2}+\left(\varepsilon_{2}\right)_{+}^{2}+\left(\varepsilon_{3}\right)_{+}^{2}}$

where: $\left(\varepsilon_{i}\right)_{+}$represents the positive components of the main strain tensor.

The complex mechanical behaviour of the concrete, which have different mechanical responses for tensile and compressive stresses, is accounted by the Mazars's damage model. This model evaluates the mechanical damage, $D$, through two independent damage variables $D_{T}$ and $D_{C}$, which account for the damage on tensile and compressive cases, respectively.

$D_{T}$ and $D_{C}$ are evaluated by internal Mazars's parameters model. Moreover, the internal Mazars's parameters model are calibrated utilizing experimental results for uniaxial tensile and compressive tests. Thus, the damage variables are calculated as follows:

$D_{T}=1-\frac{\varepsilon_{d 0}\left(1-A_{T}\right)}{\tilde{\varepsilon}}-\frac{A_{T}}{e^{\left[B_{T}\left(\tilde{\varepsilon}-\varepsilon_{d 0}\right)\right]}}$

$D_{C}=1-\frac{\varepsilon_{d 0}\left(1-A_{C}\right)}{\tilde{\varepsilon}}-\frac{A_{C}}{e^{\left[B_{C}\left(\tilde{\varepsilon}-\varepsilon_{d 0}\right)\right]}}$

where: $A_{T}$ and $B_{T}$ are internal tensile parameters; $A_{C}$ and $B_{C}$ area internal compressive parameters. Mazars [19] proposed a range of values for these parameters, which are represented in Equation (24).

$0.7 \leq A_{T} \leq 1 ; 1 \leq A_{C} \leq 1.5 ; 10000 \leq$

$B_{T} \leq 100000 ; 1000 \leq B_{C} \leq 2000$

The scalar damage variable $D$ is evaluated by a linear composition of the independent variables $D_{T}$ and $D_{C}$ as follows:

$D=\alpha_{T} D_{T}+\alpha_{C} D_{C}$

The weigh coefficients $a_{T}$ and $\alpha_{C}$ depend on the nature of the stress state at the analysed material point. In the present study, these coefficients are evaluated by utilizing the procedure proposed by Perego [27]:

$\alpha_{T}=\frac{\sum_{i}\left(\underline{\varepsilon}_{T i}\right)_{+}}{\underline{\varepsilon}_{V}^{+}} ; \quad \alpha_{C}=\frac{\sum_{i}\left(\underline{\varepsilon}_{C i}\right)_{+}}{\underline{\varepsilon}_{V}^{+}}$

where: $\underline{\varepsilon}_{T i}$ and $\underline{\varepsilon}_{C i}$ are the normal strain components obtained from the main strains, assuming linear elastic material behaviour; $\underline{\varepsilon}_{V}^{+}$corresponds to the kinematic variable that represents the local elongation state defined as follows:

$\underline{\varepsilon}_{V}^{+}=\sum_{i}\left(\underline{\varepsilon}_{T i}\right)_{+}+\sum_{i}\left(\underline{\varepsilon}_{C i}\right)_{+}$

The Mazars's damage model is isotropic. Therefore, the constitutive material relation, stress $\times$ strain, is defined by assuming that the scalar damage variable $D$ penalizes equally all components of the elastic stiffness tensor $D$. Thus, the constitutive relation in this damage model is written as follows:

$\underline{\sigma}=(1-D) \underline{\underline{D}}_{S} \underline{\varepsilon}$

where: $\underline{\sigma}$ is the stress tensor with normal and shear stresses components; $\underline{\varepsilon}$ is the total strain tensor.

To assess the mechanical material integrity, Equation (28) is evaluated at each numerical integration point positioned along the finite element domain. This procedure leads to the stress distribution in the equilibrium configuration, which accounts for the material nonlinear mechanical behaviour. Then, the stresses values enables determining the internal efforts. Finally, the material equilibrium condition is compared against the external loading to verify the convergence during the incremental iterative procedure. 


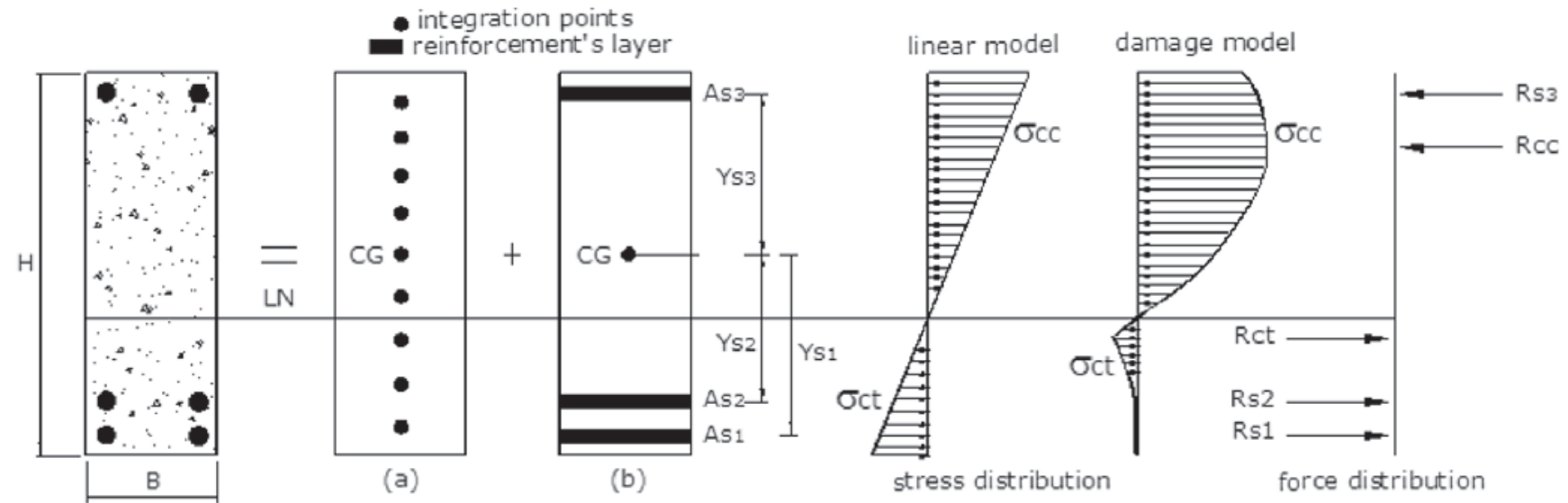

Figure 6

Numerical integration scheme

The reinforcements' mechanical behaviour is described by the elastoplasticity theory in the proposed model. An elastoplastic model with positive linear isotropic hardening is utilized for describing the reinforcements' mechanical nonlinear behaviour. This approach allows representing the residual strains during any unloading process. The plasticity criterion utilized in this model is written as follows:

$f=\sigma_{S}-\left(f_{y}+K \alpha\right) \leq 0$

where: $s_{s}$ is the active normal stress at the reinforcement; $f_{y}$ is the reinforcements' yield stress; $K$ corresponds to the plastic hardening modulus and $\alpha$ is the measure of the equivalent plastic strain.
Therefore, the normal stress at the reinforcements is described as a function of $f$ as follows:

$f \leq 0 \rightarrow \sigma_{S}=E_{S} \varepsilon$

$f>0 \rightarrow \sigma_{S}=E_{S}^{\prime} \varepsilon$

where: $E_{S}$ is the reinforcement Young's modulus; $E_{S}^{\prime}$ is the updated material stiffness modulus, which accounts for the steel hardening domain. $E_{S}^{\prime}=0$. for nil hardening case and $E_{S}^{\prime}=\left(E_{S} K\right) /\left(E_{S}+K\right)$ for non-nil hardening case.

The nonlinear mechanical problem modelled by the damage mechanics and the elastoplastic criterion is solved with a Newton-
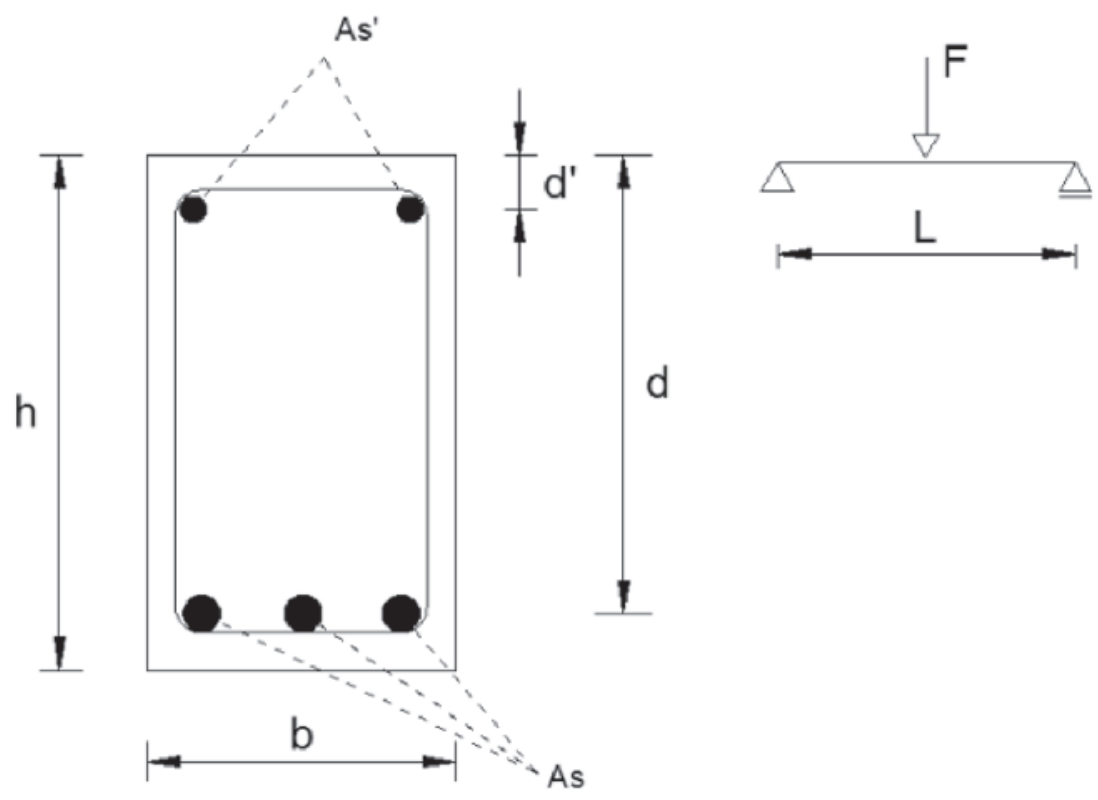

d

Figure 7

Static scheme and beam design Au e Bai [7] 
Table 1

Dimensions and reinforcements for the beams tested by Au and Bai [7]

\begin{tabular}{|c|c|c|c|c|c|c|c|c|}
\hline Beam & $\mathbf{L}(\mathbf{m m})$ & $\mathbf{b}(\mathbf{m m})$ & $\mathbf{h}(\mathbf{m m})$ & $\mathbf{d}(\mathbf{m m})$ & $\mathbf{d}^{\prime}(\mathbf{m m})$ & $\mathbf{A}_{\text {sT }}$ & $\mathbf{A}_{\text {sC }}$ & $\mathbf{A}_{\text {sw }}$ \\
\hline B1 & 2600 & 200 & 300 & 260 & 30 & $3 \phi 16$ & $2 \phi 12$ & $\phi 12 \mathrm{c} / 175$ \\
\hline B2 & 2600 & 200 & 300 & 250 & 30 & $2 \phi 25$ & $2 \phi 12$ & $\phi 12 \mathrm{c} / 175$ \\
\hline
\end{tabular}

\section{Table 2}

Concrete and steel proprieties adopted in the beams tested by Au e Bai [7]

\begin{tabular}{|c|c|c|c|c|c|c|c|}
\hline Beam & $\mathbf{f}_{\mathrm{CC}}(\mathbf{M P a})$ & $\mathbf{f}_{\mathrm{CT}}(\mathbf{M P a})$ & $\mathbf{E}_{\mathrm{c}}(\mathbf{G P a})$ & $\mathbf{f}_{\mathrm{Y}}(\mathbf{M P a})$ & $\mathbf{E}_{\mathrm{s}}(\mathbf{G P a})$ & $\mathbf{f}_{\mathrm{Yw}}(\mathbf{M P a})$ & $\mathbf{E}_{\mathrm{sw}}(\mathbf{G P a})$ \\
\hline $\mathrm{B} 1$ & 52.0 & 4.5 & 27.0 & 488.0 & 200.0 & 328.0 & 186.0 \\
\hline B2 & 52.0 & 4.5 & 27.0 & 488.0 & 200.0 & 328.0 & 186.0 \\
\hline
\end{tabular}

Raphson scheme, Nogueira et al. [24]. The tangent stiffness matrix and the non-equilibrated internal efforts vector are determined accounting for the physical nonlinearities provid by the concrete and the steel. The mechanical contribution of the stirrups is accounted into the stiffness matrix. Moreover, the geometrical nonlinearity is accounted by using the updated-Lagrangian approach.

The numerical integration required by the proposed model is accomplished through the Gauss-Lobatto quadrature scheme. Integration points are positioned along the finite element length and cross-section. At each integration point, Equations (28) and (29) are evaluated. Consequently, the concrete damage is assessed and reinforcements' plastic strains are calculated. Thus, these information allow determining the concrete and the steel mechanical contributions, which are included into the stiffness matrix and the internal efforts vector. The reinforcements are discretized into layers along the cross-section height. Figure 6 illustrates the numerical integration scheme accomplished during the loading process.

\subsection{Nonlinear model application: beams analysed experimentally by Au and Bai [7]}

The numerical mechanical model proposed in this study was applied in the mechanical modelling of beams analysed experimentally. The beams analysed in Au and Bai [7] were utilized to prove the accuracy and robustness of the proposed model. Figure 7 presents the static scheme utilized and the applied load.

Two beams were analysed experimentally by Au and Bai [7], which varied the longitudinal reinforcements' ratio, as described in Table 1. Table 2 presents the material proprieties utilized in the modelling, which were all provided by Au and Bai [7].

As previously presented, the Mazars's damage model [19] requires the definition of internal parameters for characterizing the scalar damage variable, Eq. (24). Due to the absence of experimental data, these parameters were evaluated by the approaches presented in Popovics [28], for compression concrete stresses, and Figueiras [14], for tensile concrete stresses. Alternatively, the tensile parameters $\left(A_{T}\right.$ and $\left.B_{T}\right)$ were also calculated by utilizing the exponential decay approach proposed in Nogueira [23]. Table 3 presents the damage parameters utilized in the present analysis. The finite element mesh was determined via convergence process. A beam was mechanically analysed utilizing 8, 12, 16, 20 and 24 one-dimensional finite frame elements with the same length. Then, the collapse load values for each discretization were compared. The difference between the collapse load values into two successive meshes was compared. The following differences were observed: 8 to 12 elements, difference $=3.9 \% ; 12$ to 16 elements, difference $=2.0 \% ; 16$ to 20 elements, difference $=1.2 \% ; 20$ to 24 elements, difference $=0.4 \%$. Therefore, based on these results, the mesh with 24 finite frame element was adopted for further analysis. The mechanical modelling was accomplished based on the Timoshenko's theory, with transversal reinforcements' contribution (TS). Moreover, the reinforcements were modelled assuming nil hardening case, i.e., $\mathrm{K}=0$.

The damage parameters utilized in the proposed model were calculated either by the Popovics-Figueiras approach (TS-Fig) or Popovics-Nogueira approach (TS-Expon). Figures 8 and 9 illustrate the equilibrium paths for beams B1 and B2, respectively. As presented in these last two figures, good agreement is observed among the results achieved by the proposed numerical model and the experimental responses. It is worth emphasizing that the numerical model proposed is unidimensional with perfect adherence assumption between steel and concrete. The numerical

Table 3

Damage parameters adopted for concrete

\begin{tabular}{|c|c|c|c|c|c|c|}
\hline \multirow{2}{*}{ Beam } & \multicolumn{2}{|c|}{ Popovics [28] } & \multicolumn{2}{c|}{ Figueiras [14] } & \multicolumn{2}{c|}{ Nogueira [23] } \\
\cline { 2 - 7 } & $\mathbf{A}_{\mathrm{C}}$ & $\mathbf{B}_{\mathrm{C}}$ & $\mathbf{A}_{\boldsymbol{T}}$ & $\mathbf{B}_{\boldsymbol{T}}$ & $\mathbf{A}_{\boldsymbol{T}}$ & $\mathbf{B}_{\boldsymbol{T}}$ \\
\hline B1 & 1.790 & 1241.886 & 0.772 & 5837.209 & 0.938 & 5417.491 \\
\hline B2 & 1.790 & 1241.886 & 0.772 & 5837.209 & 0.938 & 5417.491 \\
\hline
\end{tabular}




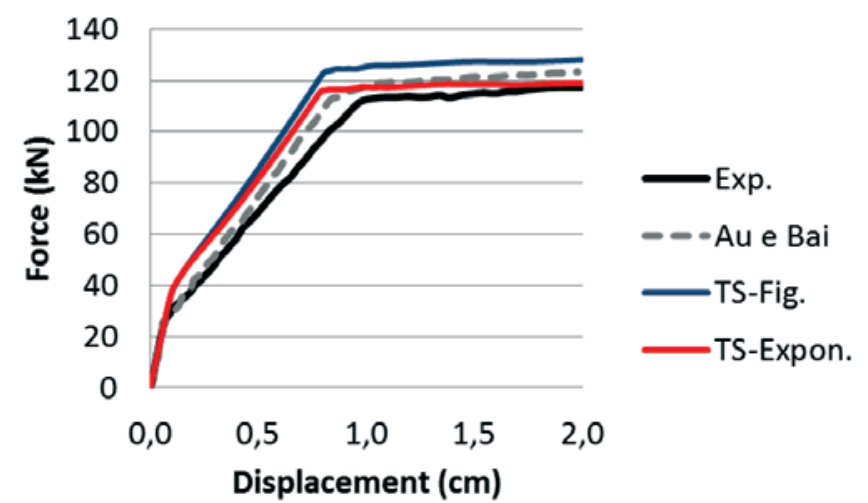

Figure 8

Equilibrium path for beam B1

model utilized by Au and Bai [7] is bidimensional, with embedded reinforcements and adherence loss assumption. However, the numerical responses presented in Figures 8 and 9 are extremely similar. Therefore, based on the results presented in Figures 8 and 9 , the accuracy and robustness of the proposed model was proved. In spite of the simplifications assumed, the model is capable to represent the experimental mechanical behaviour of reinforced concrete beams. Moreover, the results provided by the proposed model are equivalent to more complex and expensive numerical models available in the literature, such as the one presented by Au and Bai [7].

\section{Mechanical resistance loss due to the reinforcements' corrosion}

The purpose of the analyses carried out in this item is demonstrating the influence of reinforcements' corrosion upon the mechanical behaviour of isostatic reinforced concrete beams. The mechanical degradation caused by the reinforcements' corrosion evolves along time and is composed by some particular effects such as reinforcements' cross-section reduction and steel yield strength reduction, for instance. Thus, the numerical mechanical model proposed in this study is applied in the mechanical analysis of reinforced concrete beams subjected to reinforcements' corrosion in order to assess the influence of each of these parameters. Figure 10 presents the beam utilized in the analysis with its geometry, cross-section dimensions, reinforcements' details and applied load.

For each assumption accomplished upon the corrosion process modelling, the collapse load value was determined along time. In

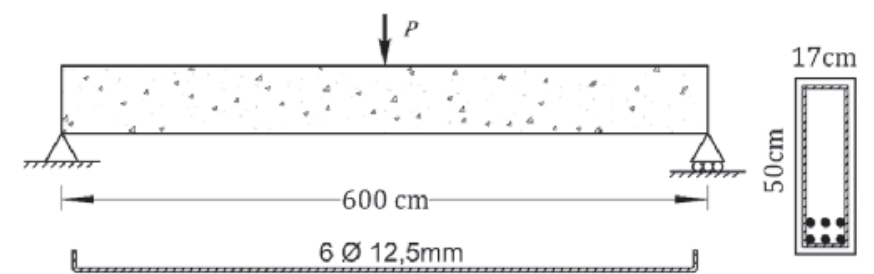

Figure 10

Analysed reinforced concrete beam

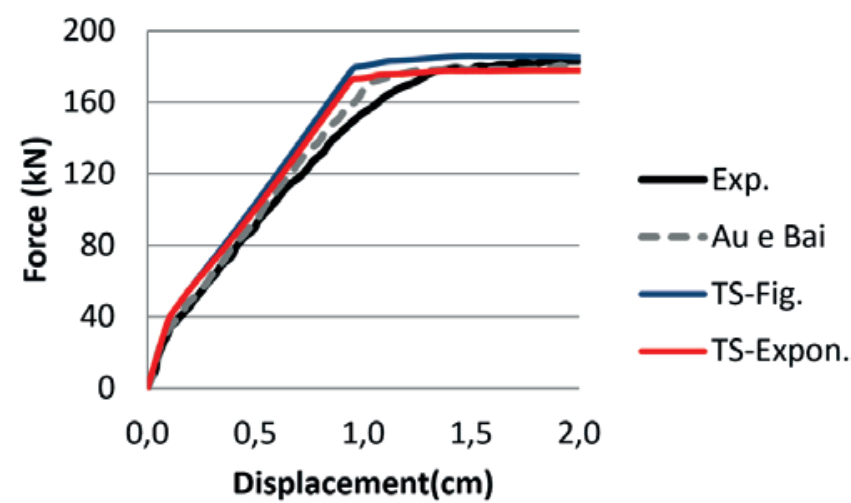

Figure 9

Equilibrium path for beam B2

addition to the mechanical numerical model proposed in this study, the equilibrium equations proposed by the ABNT NBR 6118:2014 were also utilized for determining the collapse structural load.

The ultimate limit state based on the ABNT NBR 6118:2014 is given by Equation (19). Then, the collapse load value is determined according to the resistant bending moment provided by the Equation (19). The ultimate limit state into the numerical mechanical model is defined utilizing threshold values for strains at concrete and steel. Therefore, the mechanical collapse in such a case is observed when the normal strain at the concrete reaches $-3.5 \%$ or 10 $\% o$ at the reinforcements' steel. Thus, the load intensity that leads to any or both the threshold strains values previously presented is defined as collapse load value.

The analyses were accomplished assuming the following parameters values: characteristic compression concrete strength $30 \mathrm{MPa}$; concrete Young's modulus $28 \mathrm{GPa}$; concrete Poisson's ratio 0.2; reinforcements yield strength $500 \mathrm{MPa}$; reinforcements Young's modulus $196 \mathrm{GPa}$; reinforcements plastic modulus $19.6 \mathrm{GPa}$. The dimensions for concrete cover and useful height are $3.0 \mathrm{~cm}$ and $44.12 \mathrm{~cm}$, respectively.

The numerical mechanical model proposed in this study simulates the mechanical behaviour by applying the load into 100 load steps with tolerance of $10^{-4}$ for convergence during the incremental iterative process. The damage parameters adopted for the Mazars's damage model are the following: $A_{T}=0.7 ; B_{T}=10000 ; A_{C}=1.5$; $B_{C}=2000 ; e_{d 0}=6.41 \times 10^{-5}$. The numerical integration required for evaluating the stiffness matrix and the load vector was carried out utilizing 6 integration points along the element length and 20 integration points along the cross-section high.

The growth of the chloride concentration into the concrete pores along time was modelled via Fick's second law. The uniform corrosion approach was adopted for penalizing the reinforcements' cross-section area. The following parameters values associated to the corrosion process were adopted:

- Threshold chloride concentration value $\left(\mathrm{C}_{\text {lim }}\right): 0.9 \mathrm{~kg} / \mathrm{m}^{3}(\mathrm{Vu}$ e Stewart [36]);

- Chloride concentration at the external surfaces $\left(C_{0}\right): 1.15 \mathrm{~kg} / \mathrm{m}^{3}$ (McGee [20]). Such a concentration was assumed as constant and uniform along all exposed structural surfaces;

- Concrete coefficient of diffusion $\left(D_{0}\right): 67.42 \mathrm{~mm}^{2} /$ year (Equation 6); 
Table 4

Specification of time dependent analyses

\begin{tabular}{|c|c|c|c|c|c|}
\hline $\begin{array}{c}\text { Analysis } \\
\text { number }\end{array}$ & $\begin{array}{c}\text { Mechanical } \\
\text { model }\end{array}$ & $\begin{array}{c}\text { Time dependent } \\
\text { corrosion rate? }\end{array}$ & $\begin{array}{c}\text { Time dependent } \\
\text { steel yield } \\
\text { stress? }\end{array}$ & $\begin{array}{c}\text { w/c ratio } \\
\text { randomness } \\
\text { over the finite } \\
\text { elements? }\end{array}$ & $\begin{array}{c}\text { Number of finite } \\
\text { elements in the } \\
\text { mesh }\end{array}$ \\
\hline 1 & NBR 6118 & No & No & - & No \\
\hline 2 & FEM & No & No & No & 10 \\
\hline 3 & FEM & Yes & No & Yes & 10 \\
\hline 4 & FEM & Yes & No & Yes & 10 \\
\hline 5 & FEM & Yes & No & Yes & 100 \\
\hline 6 & FEM & Yes & Yes & \\
\hline
\end{tabular}

w/c ratio: 0.5

- Time increment for corrosion evolution $\left(\mathrm{Dt}_{\mathrm{p}}\right)$ : 2 years.

To assess the influence of each phenomenon evolved into the corrosion process upon the mechanical behaviour of reinforced concrete beams, mechanical analyses considering the hypotheses modelling described in Table 4 were accomplished. The goal of these analyses is achieving the collapse load value. Thus, this result is compared among the several scenarios analysed.

The reinforcements' corrosion phenomenon may be triggered differently at the points along the beam length. This observation occurs due to the presence of initial cracks, which appear during the concrete cure and facilitate the chloride ingress. To simulate this practical observation, the number of finite elements into the mesh and the w/c ratio at each finite element were varied. Therefore, the time for corrosion initiation change at each finite element utilized in the mesh, which enables simulating different time for corrosion initiation. This scenario was assumed to reproduce more realistically the real corrosion phenomenon. In this scenario, the w/c ratio value was determined randomly, in which each finite element has a specific value. These values were achieved from an uniform probability distribution with mean 0.5 and coefficient of variation $11.5 \%$. The Figure 11 presents the results for the collapse load value $x$ time for all scenarios analysed. It is important mentioning that the time was accounted after the corrosion initiation. Among the scenarios analysed, the collapse load value provided by the ABNT NBR 6118:2014 approach was the lowest at $t_{p}=0$. The ABNT NBR 6118:2014 approach does not account for the tensile concrete strength, which may explain the behaviour. Otherwise, the Mazars's damage model represents accurately the strength contribution provided by the tensile concrete. Therefore, the sum of the tensile concrete strength along the whole beam length increases slightly the mechanical structural resistance.

From the structure born to the time for corrosion initiation, the scenarios considered in the analyses 5 and 6 provided the lowest collapse load value among the scenarios simulated into the numerical mechanical model proposed. Such a behaviour may be explained due to the discretization adopted, which is composed by 100 finite elements instead of the 10 finite elements utilized in the others numerical simulations. It causes the growth of the degrees of freedom in the modelling. The scenarios considered in the analyses 2 , 3 and 4 provided collapse load values $25 \%$ higher than the same load value achieved in the analysis 1 . Moreover, these scenarios provided collapse load values $18 \%$ higher than the collapse load values observed in analyses 5 and 6 .

After 35 years from the corrosion initiation start, the longitudinal reinforcements' cross-section area become nil. Thus, the mechanical resistance calculated via ABNT NBR 6118:2014, Equation (19), results nil. Otherwise, the numerical mechanical model proposed assesses the mechanical strength exclusively by the mechanical concrete contribution when the reinforcements' cross-section area become nil. In this case, the concrete damage at the tensile crosssection part is high, i.e., the $D$ value tends to one. At the compression cross-section part, $\mathrm{D}$ tends progressively to one during the evolution of the mechanical collapse process. The scenarios simulated with the numerical model proposed result the collapse load value tending to $17 \mathrm{kN}$ for nil reinforcements' cross-section area.

The scenario simulated in analysis 2 assumes the corrosion rate, $\mathrm{i}_{\text {corr }}$, as time independent. Therefore, this scenario leads to an extremely severe corrosion evolution, which causes faster decrease over the reinforcements' cross-section area and, consequently, faster decrease over the mechanical structural strength. As a

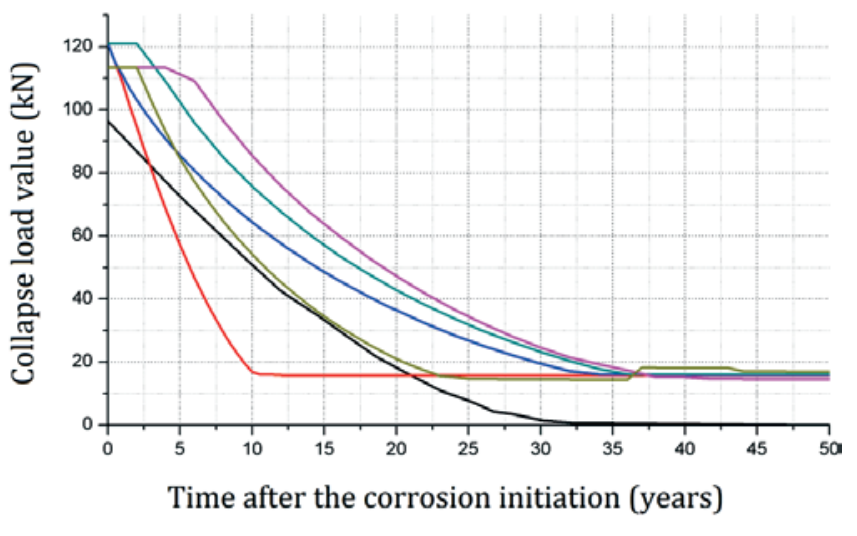

- Analysis 1 - Analysis $2-$ Analysis 3

Figure 11

Collapse load value reduction along time. Time considered after the time for corrosion initiation 
result, this scenario observes the end of reinforcements' crosssection 10 years after the corrosion start. Oppositely to the other scenarios, in which the reinforcements' end 35 years after the corrosion start.

Table 5 illustrates the evolution of the collapse load values rate along time for the scenarios and models simulated. The analysis 2 , in which corrosion rate and reinforcements' yield stress are time independent, resulted the higher strength rate decrease along time. This scenario resulted $10.4 \mathrm{kN} /$ year as average rate in the beginning of the corrosion process.

The scenarios 2 and 3 differ from the time independence and dependence, respectively, of the corrosion reinforcements' rate, $i_{\text {corr }}$. In spite of this single difference, the mechanical behaviour observed on each of these analyses strongly changed due to this hypothesis modelling. The reinforcements' cross-section area reduction is less severe in scenario 3 due to the time dependence of $i_{\text {corr }}$. This result illustrates the influence of the corrosion rate upon the mechanical behaviour of reinforced concrete structures subjected to reinforcements' corrosion along time.

The analyses 4, 5 and 6 consider a non-uniform w/c ratio along the beam length. In these scenarios, each finite element may have a different $w / c$ ratio value. This hypothesis modelling enables simulating the influence of the initial concrete cracking, which appears due to the concrete cure process. Then, along the beam positions where the initial cracking occurs faster chloride ingress is observed. As a result, different time for corrosion initiation is simulated at each finite element by utilizing this procedure once $D_{0}$ may change at each finite element. Consequently, it leads to a more realistic reinforcements' corrosion process modelling. Because the time for corrosion initiation may be different at each finite element, the mechanical effects caused by the reinforcements' corrosion start in different time instant. This hypothesis modelling explains the short time instant, just after the reinforcements' corrosion start, in which the collapse load value is approximately constant. In this short period, the reinforcements' corrosion occurs. However, it starts at isolated finite elements and its influence is not sufficient for changing significantly the global mechanical behaviour.

Finally, the mechanical behaviour achieved in analysis 6 is quite different from the others scenarios simulated, especially 3,4 and 5 . Such a behaviour is observed because the analysis 6 accounts for the reduction of reinforcements' yield strength along time. Therefore, this corrosion effect coupled to the nonlinearities arising from the structural materials leads to the mechanical behaviour observed.

\section{Conclusions}

The present study proposed a numerical model to represent the mechanical behaviour of reinforced concrete beams subjected to reinforcements' corrosion. The model is composed by the coupling of damage mechanics, elastoplasticity theory, which were introduced in a FEM computational code. The mechanical effects introduced by the corrosion process are considered by empirical approaches presented in the literature. The conclusions of this study are pointed as follows:

- The numerical model proposed proved its efficiency in the modelling of the mechanical behaviour of reinforced concrete beams, see example 1. The damage mechanics coupled to the elastoplasticity theory is adequate for this purpose. Moreover, the model is stable and non-convergence cases were not observed. The model validation with other numerical examples as described in section 3.2 can be seen in Nogueira et al. [24];

- The time-dependence of the corrosion rate is more realistic than its time-independence. As the corrosion progress, the material transformation caused by the electrochemical processes tends to stabilize along time. The steel degradation is intense in the corrosion beginning and tends to stabilize along time. Therefore, the hypotheses assumed in analyses 3 to 6 are more realistic and consistent than the assumed in analysis 2;

- The strength reduction rate caused by the reinforcements' corrosion is intense just after the corrosion time initiation;

- The yield stress reduction along time caused by the reinforcements' corrosion is an important phenomenon and have strong influence over the mechanical behaviour during the corrosion. The results achieved in analysis 6 illustrates clearly such an importance. The hypothesis of time dependence for the reinforcements yield stress is more realistic, once the steel internal microstructure is changed due to the electrochemical processes;

\section{Table 5}

Evolution of the mechanical strength in terms of average annual rate

\begin{tabular}{|c|c|c|c|c|c|c|}
\hline \multirow{2}{*}{$\begin{array}{c}\text { Time after the reinforcements' depassivation } \\
\text { (years) }\end{array}$} & \multicolumn{7}{|c|}{ Average collapse load value reduction (kN/year) } \\
\cline { 2 - 7 } & \multicolumn{7}{|c|}{ Analysis number } \\
\cline { 2 - 7 } & $\mathbf{1}$ & $\mathbf{2}$ & $\mathbf{3}$ & $\mathbf{4}$ & $\mathbf{5}$ & $\mathbf{6}$ \\
\hline $0-5$ & 4.4 & 12.8 & 7.1 & 2.4 & 0.9 & 5.8 \\
\hline $5-10$ & 3.8 & 8.1 & 4.2 & 6.7 & 5.6 & 6.1 \\
\hline $10-15$ & 3.8 & 0.2 & 3.2 & 3.1 & 3.6 & 3.9 \\
\hline $15-20$ & 2.6 & 0.0 & 2.4 & 3.5 & 4.1 & 2.7 \\
\hline $20-25$ & 2.9 & 0.0 & 1.6 & 1.8 & 2.1 & 1.2 \\
\hline $25-30$ & 1.2 & 0.0 & 1.8 & 2.1 & 2.4 & 0.1 \\
\hline $30-35$ & 0.1 & 0.0 & 0.7 & 1.1 & 1.1 & 0.0 \\
\hline
\end{tabular}


The scheme of generating different $w / c$ ratio value at each finite element presents an improvement as the mesh grows. This procedure allows simulating a pitting corrosion case, which is characteristic of the chloride induced reinforcements' corrosion. Then, this technique enables a more realistic modelling once the reinforcements at each finite element are penalized uniformly along the element length.

It is worth to mention that the adherence loss between steel and surrounding concrete as a consequence of the corrosion phenomenon was not take into account in this study.

\section{Acknowledgement}

Sponsorship of this research project by São Paulo Research Foundation (FAPESP), grant number 2014/18928-2 is sincerely appreciated. The authors thank José Vitor de Lira Haraki for the contribution in preparing one example (item 3.3).

\section{References}

[1] ALMUSALLAM, A. Effect of degree of corrosion on the properties of reinforcing steel bars. Construction and Building Materials, v. 15, 2001, p. 361-368.

[2] AlMUSAlLAM, A.; AL-GAHTANI, A.S.; AZIZ, A.R.; RASHEEDUZZAFAR. Effect of reinforcement corrosion on bond strength. Construction and Building Materials, v. 10, n. 2, 1996, p. 123-129.

[3] APOStOlOPOUlOS, C.A.; PAPAdAKIS, V.G. Consequences of steel corrosion on the ductility properties of reinforcement bar. Construction and Building Materials, v. 22, n. 12, 2008, p. 2316-2324.

[4] ASSOCIAÇÃO BRASILEIRA DE NORMAS TÉCNICAS (ABNT). Projeto de estruturas de concreto - procedimento (NBR 6118), Rio de Janeiro, 2014, 238 p.

[5] AU, F.T.K.; BAI, Z.Z. Two-dimensional nonlinear finite element analysis of monotonically and non-reversed cyclically loaded RC beams. Engineering Structures, v. 29, 2007, p. 2921-2934.

[6] BASTIDAS-ARTEAGA, E.; CHATEAUNEUF, A.; SÁNCHESSILVA, M.; BRESSOLETTE, P.; SCHOEFS, F. A comprehensive probabilistic model for chloride ingress in unsaturated concrete. Engineering Structures, v. 51, 2011, p. 259-266.

[7] Bentz, D.P.; Clifton, J.R.; Snyder, K.A. Predicting service life of chloride-exposed reinforced concrete. Concrete International, v.18 (12), 1996, p. 42-47.

[8] BIONDINI, F.; CAMNASIO, E.; FRANGOPOL, D.M.; MALERBA, P.G. Probabilistic service life assessment and maintenance planning of concrete structures. ASCE Journal of Structural Engineering, v. 132, 2006, p. 810-825.

[9] BIONDINI, F.; CAMNASIO, E.; PALERMO, A. Lifetime seismic performance of concrete bridges exposed to corrosion. Structure and Infrastructure Engineering, v. 10, 2014, p. 880-900.

[10] BIONDINI, F.; VERGANI, M. Deteriorating beam finite element for nonlinear analysis of concrete structures under corrosion. Structure and Infrastructure Engineering, v. 11, n. 4, 2015, p. 519-532.

[11] COMITÉ EURO-INTERNATIONAL DU BÉTON. Durable con- crete structures - design guide (CEB). Bulletin d'information n. 183, London, 1992, Thomas Telford.

[12] Crank, J. The mathematics of diffusion. 2nd ed., Oxford (London): Clarendon Press, 1975, p.414.

[13] DU, Y.G.; CLARK, L.A.; CHAN, A.H.C. Residual capacity of corroded reinforcing bars. Magazine of Concrete Research, v. 57 , n. 3, 2005, p. 135-147.

[14] FIGUEIRAS, J.A. Ultimate load analysis of anisotropic and reinforced concrete plates and shells. Ph.D. Thesis, Department of Civil Engineering, University College of Swansea, 1983;

[15] GONZALEZ, J.A.; ANDRADE, C.; ALONSO, C.; FELIU, S. Comparison of rates of general corrosion and maximum pitting penetration on concrete embedded steel reinforcement. Cement and Concrete Research, v. 25, 1995, p. 257-264.

[16] GUZMÁN, S.; GÁLVEZ, J.C.; SANCHO, J.M. Cover cracking of reinforced concrete due to rebar corrosion induced by chloride penetration. Cement and Concrete Research, v. 41, 2011, p. 893-902.

[17] LIBERATI, E.A.P.; NOGUEIRA, C.G.; LEONEL, E.D.; CHATEAUNEUF, A. Nonlinear formulation based on FEM, Mazars damage criterion and Fick's law applied to failure assessment of reinforced concrete structures subjected to chloride ingress and reinforcements corrosion. Engineering Failure Analysis, v. 46, 2014, p. 247-268.

[18] MATSUMURA, T.; SHIRAI, K.; SAEGUSA, T. Verification method for durability of reinforced concrete structures subjected to salt attack under high temperature conditions. Nuclear Engineering and Design, v. 238, n. 5, 2008, p. 1181-1188.

[19] MAZARS, J. Application de la mechanique de l'endommagement au comportement non lineaire et à la rupture du béton de structure. Thèse de Doctorat d'État, Université Paris 6, 1984, Paris.

[20] McGEE, R. Modelling of durability performance of Tasmanian bridges. In: Melchers R.E., Stewart M.G., editors. ICASP8 applications of statistics and probability in civil engineering, v. 1, 1999, p. 297-306.

[21] MEHTA, P.K.; MONTEIRO, P.J.M. Concreto: microestrutura, propriedades e materiais. São Paulo, Ibracon, $3^{\text {ed }}, 2008$, $674 \mathrm{p}$.

[22] NEVILLE, A.M. Propriedades do concreto. $5^{\mathrm{a}}$ edição, Porto Alegre: Bookman, tradução: Ruy Alberto Cremonini, 2016, $888 \mathrm{p}$.

[23] NOGUEIRA, C.G. Modelo mecânico para estruturas lineares em concreto armado - uma abordagem acoplada entre a mecânica do dano e algoritmos de otimização. Engenharia Estudo e Pesquisa, Santa Maria, v. 12, n. 2, jul./dez., 2012, p. 14-27.

[24] NOGUEIRA, C.G.; VENTURINI, W.S.; CODA, H.B. Material and geometric nonlinear analysis of reinforced concrete frame structures considering the influence of shear strength complementary mechanisms. Latin American Journal of Solids and Structures, v. 10, 2013, p. 953-980.

[25] OZBOLT, J.; BALABANIC, G.; KUSTER, M. 3D numerical modelling of steel corrosion in concrete structures. Corrosion Science, v. 53, 2011, p. 4166-4177. 
[26] PAPADAKIS, V.G.; ROUMELIOTIS, A.P.; FARDIS, M.N.; VAGENAS, C.G. Mathematical modelling of chloride effect on concrete durability and protection measures. In: Dhir RK, Jones MR, editors. Concrete repair, rehabilitation and protection, London (UK): E\&FN Spon, 1996, p.165-174.

[27] PEREGO, M.A. Danneggiamento dei materiali lapidei: leggi constitutive, analisi per elementi finiti ed applicazioni. Tesi di Laurea, Politecnico di Milano, 1990, Milano.

[28] POPOVICS, S. A numerical approach to the concrete stressstrain curve of concrete. Cement and Concrete Research, v. 3, 1973, p. 583-599.

[29] SAMSON, E.; MARCHAND, J.; SNYDER, K.A. Calculation of ionic diffusion coefficients on the basis of mitigation test results. Materials and Structures, v. 36, 2003, p. 156-165.

[30] SCHMITT, G. Global needs for knowledge dissemination, research and development in materials deterioration and corrosion control. World Corrosion Organization, May, 2009, 44 p.

[31] SUO, Q.; STEWART, M.G. Corrosion cracking prediction updating of deteriorating RC structures using inspection information. Reliability Engineering and System Safety, v. 94, 2009, p. 1340-1348.

[32] TUUTTI, K. Corrosion of steel in concrete. Swedish cement and concrete research institute, Stockholm, 1982.

[33] VAL, D.V.; MELCHERS, R.E. Reliability of deteriorating RC slab bridges. Journal of Structural Engineering (ASCE), v. 123, n. 12, 1997, p. 1638-1644.

[34] VAL, D.V.; STEWART, M.G. Life-cycle cost analysis of reinforced concrete structures in marine environments. Structural Safety, v. 25, n. 4, 2003, p. 343-362.

[35] VAL, D.V.; CHERNIN, L.; STEWART, M.G. Experimental and numerical investigation of corrosion-induced cover cracking in reinforced concrete structures. ASCE Journal of Structural Engineering, v. 135, 2009, p. 376-385.

[36] VU, K.A.T.; STEWART, M.G. Structural reliability of concrete bridges including improved chloride-induced corrosion models. Structural Safety, v. 22, n. 4, 2000, p. 313-333.

[37] ZHANG, R.; CASTEL, A.; FRANÇOIS, R. Concrete cover cracking with reinforcement corrosion of $\mathrm{RC}$ beam during chloride-induced corrosion process. Cement and Concrete Research, v. 40, 2010, p. 415-425. 